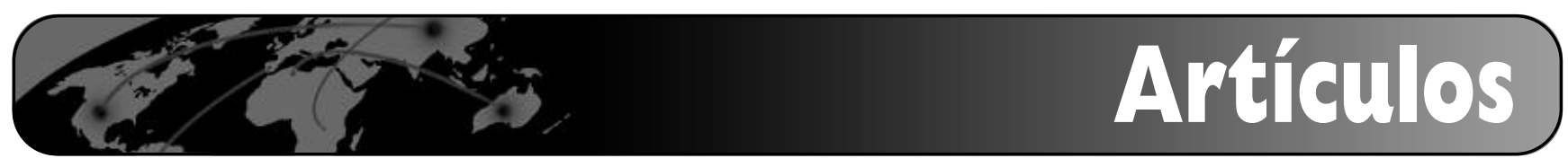

\title{
Propiedad intelectual y documentación audiovisual: derecho de autor en las bases de datos de las cadenas de televisión
}

\author{
Por Julián Rodríguez Pardo y María Victoria Nuño Moral
}

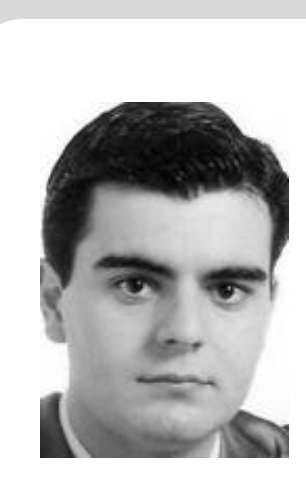

Julián Rodríguez Pardo es profesor de la licenciatura de comunicación audiovisual de la Universidad de Extremadura. Especialista en ética y derecho de la información, ha publicado el libro Copyright and multimedia, con Kluwer Law International, en 2003. Ha sido Academic visitor del Programme in comparative media law \& policy, del Centre for Socio-Legal Studies de la University of Oxford. Se doctoró en ciencias de la información por la Universidad de Navarra en septiembre de 2000 .
Resumen: Este artículo estudia los aspectos específicos del derecho de autor relacionados con el trabajo informativo-documental. Se centra en las bases de datos audiovisuales desde una doble perspectiva: por un lado, la base de datos como "archivo" y, en segundo lugar, la procedencia y categorías a efectos del derecho de autor de los diferentes materiales que en ellas se almacenan.

Palabras clave: Propiedad intelectual, Derechos de autor, Documentación audiovisual, Bases de datos, Noticias, Televisión.

\section{Title: Intellectual property rights and audio-visual documentation: copy- right on the databases of television companies}

Abstract: This article examines aspects of copyright related to informative documentation. It focuses on audio-visual databases from a double perspective: on the one hand, the database as "archive" and, on the other, copyright aspects relating to the sources and different categories of the materials contained within the archive.

Keywords: Intellectual property, Copyright, Audio-visual documentation, Databases, News, Television.

Rodríguez Pardo, Julián; Nuño Moral, María Victoria. "Propiedad intelectual y documentación audiovisual: derecho de autor en las bases de datos de las cadenas de televisión". En: El profesional de la información, 2004, noviembre-diciembre, v. 13, n. 6, pp. 408-420.
$M^{a}$ Victoria Nuño Moral, licenciada (1991) y doctora (1997) en ciencias de la información por la Universidad Complutense de Madrid donde comenzó su labor docente e investigadora en 1991, en el Depto. de Biblioteconomía y Documentación. Actualmente es profesora titular de la Universidad de Extremadura donde imparte las asignaturas de documentación informativa y documentación audiovisual desde 1999 en la Facultad de Biblioteconomía y Documentación. Es autora de diversas publicaciones sobre documentación en los medios de comunicación y coautora de dos monografías relacionadas con esta área: Diseño de una base de datos de imágenes para televisión y Gestión de la documentación en la publicidad y en las relaciones públicas. Su experiencia profesional e investigadora le ha llevado a participar como ponente en diferentes congresos nacionales e internacionales. Igualmente ha colaborado en diversos proyectos de investigación tanto en la UCM como en la UEX, dirigiendo el proyecto Nuevas tecnologías y sistemas hipertextuales aplicados a la prensa, dentro del I Plan Regional de Investigación y Desarrollo Tecnológico (1999-2002).

\section{Introducción: la gestión de las bases de datos audiovisuales}

No es posible analizar el modo en que el derecho se hace con las distintas realidades sin conocer previamente en qué consisten éstas. De ahí que en las próximas líneas nos adentremos en cuál es el papel que juegan las bases de datos audiovisuales en el medio televisivo.
No cabe duda de que la información es el recurso más valioso con el que actualmente cuenta el ser humano, y la documentación, a este respecto, permite que se encuentre a su alcance y disposición con mayor comodidad y rapidez, de lo que se infiere el extraordinario papel que las bases de datos desempeñan hoy en cualquier medio de comunicación. En consecuencia, la finalidad es conseguir la máxima utilidad con los re- 
cursos disponibles (mediante una provechosa gestión documental) para hacer partícipe a todo un colectivo de la información.

Por todo ello, periodistas y documentalistas requieren conocimientos de ambos campos de trabajo: el profesional de la información debe conocer tanto las técnicas documentales como estar mínimamente especializado en el entorno de los medios de comunicación, siendo capaz no sólo de desarrollar las tareas propiamente documentales, sino también de anticipar futuras necesidades informativas. Por otra parte, el periodista requerirá de la documentación y acudirá a ella para conseguir una mejor comprensión de la información que comunica y para contextualizar mejor la noticia documentando él mismo, en ocasiones, sus trabajos. De ahí que en función de las peticiones del periodista y de las anticipaciones del documentalista, hayan de construirse bases de datos adecuadas a las características y funcionamiento de cada medio.

\section{«Las nuevas tecnologías plan- tean nuevos retos jurídicos que en ocasiones limitan y, otras, facilitan las tareas informativo documentales»}

Ahora bien, ninguna labor es posible hoy en cualquier estado democrático al margen de la legalidad vigente, es decir, de los límites y fronteras que los diferentes aspectos del derecho imponen a la tarea de periodistas y documentalistas. No nos referimos tan sólo a las cuestiones que atañen estrictamente al contenido de las informaciones sino, en este caso, a la misma propiedad de esas noticias y de sus fuentes documentales. En este sentido ¿existe algún límite en el uso de dicha documentación/información por parte de los medios de comunicación?

En el presente trabajo nos centramos en un área concreta: el derecho de autor en televisión y, en particular, en el uso de las informaciones de actualidad contenidas en las bases de datos audiovisuales de las cadenas de televisión ${ }^{1}$. Ineludiblemente, de su titularidad dependerá la posibilidad de su uso y en consecuencia el logro de una mayor calidad en ambas tareas.

La información/documentación audiovisual cada día cobra mayor interés para los profesionales de los medios, lo que en parte también se debe a que su aparición en la Red está incrementando y acrecentando su uso por parte de cualquier usuario.

Dentro del ámbito informativo las empresas de televisión poseen un material en ocasiones único cuyo valor cultural y patrimonial, y por qué no, también económico, se considera incalculable. Todo ello se concentra en los denominados centros de documentación, los cuales aglutinan por la demanda profesional a la que están supeditados una mayor cantidad de fuentes informativas de diferente naturaleza (material audiovisual, sonoro, foto-periodístico, visual, etc.).

Dada la necesidad de lograr cierta precisión en los términos de este trabajo y con el objeto de diferenciar la documentación audiovisual del resto de tipologías documentales, entenderemos por documento audiovisual aquel que integra imagen en movimiento y sonido.

El elemento o eje central que define el medio televisivo es la imagen y en particular aquella en movimiento. No obstante, cuando se carece de este tipo de material informativo (porque el centro no disponga de imágenes relacionadas con el hecho concreto o porque no exista material de archivo pertinente) se recurrirá a la utilización de imágenes fijas. Por otro lado, dada su característica de medio audiovisual, el contenido que se comunique estará habitualmente acompañado de elementos sonoros, con independencia de que vinieran previamente incorporados (sonido ambiente) o estén apoyados por la voz del reportero o locutor ${ }^{2}$.

Una base de datos puede considerarse como un conjunto de registros que identifican a cada una de las unidades informativo-documentales que en ella se almacenan. Actualmente, junto con aquellas de naturaleza referencial que se apoyan en el almacenamiento físico del material, encontramos las bases de datos fuente (almacenan el documento primario y secundario) o las que conservan el documento primario junto a la metainformación correspondiente, de tal forma que disponemos de la información secundaria dentro del propio documento. Con ello se consigue optimizar el proceso de recuperación de dicho material.

La llegada de la automatización provoca nuevos interrogantes en los centros de documentación. En el caso que nos ocupa nos centramos en dos de ellos: qué podemos archivar y cómo hacerlo para su posible reutilización dentro de la legalidad vigente incluyendo tanto las potenciales cesiones dentro de las propias emisoras de televisión como las dirigidas al exterior; es decir, a terceros que puedan estar interesados en hacerse con los recursos audiovisuales informativos que se posean.

$\mathrm{Y}$ es que el papel que han jugado las nuevas tecnologías ha sido clave en la nueva gestión informativa, la cual plantea lógicamente nuevos retos jurídicos que en ocasiones limitan y en otras facilitan las tareas informativo documentales.

A tenor de lo expuesto y dentro de las cuestiones legales que esta automatización plantea, uno de los objetivos que se persigue en la organización de las bases 
de datos es la seguridad y la reserva de la privacidad. Para Martin", "la seguridad de los datos se refiere a la protección de estos contra el acceso accidental o intencional por parte de personas no autorizadas y contra su indebida destrucción o alteración. La reserva se refiere al derecho de los individuos y organismos para determinar por sí mismos cuándo, cómo y en qué medida se permitirá la transmisión a terceros de la información que les concierne". Por tanto, no estamos tan sólo ante una cuestión de riservatezza o privacidad, sino también de protección de esos datos informativos en cuanto a su facilitación a terceros, cuando no se ha producido ninguna cesión contractual de los mismos.

Por su parte, la elaboración de estas informaciones depende básicamente de los materiales que llegan al centro de documentación y que proceden fundamentalmente de dos tipos de fuentes: internas y externas. Esto quiere decir que en la base o bases de datos que encontramos en los centros contamos tanto con producción propia como ajena al propio medio.

Así, y a efectos de su propiedad, en una base de datos de televisión se encuentran materiales dispares tales como: grabaciones originales o brutos (aquellas que no han pasado por ningún proceso de posproducción), y los compactados (material agrupado preferentemente según criterios temáticos procedente de la selección efectuada del material original); material editado y/o emitido en directo (paralelo) que generalmente consiste en producción propia sobre la cual la entidad televisiva conserva todos los derechos ${ }^{4}$.

Por otro lado, al centro de documentación llegan también materiales procedentes de otras fuentes de información: cabe resaltar el material de agencias tanto nacionales como internacionales; y/o enlaces o envíos de coberturas, así como adquisiciones puntuales (master).

En estos casos, y grosso modo, las cadenas de televisión cuentan con unos derechos limitados en cuanto a su uso en función del contrato establecido. Por norma su adquisición se realiza en función de un uso concreto y para un número de veces determinado, al igual que como se verá tanto periodistas como documentalistas renuncian a sus derechos de autor por vía contractual laboral.

Por este motivo, ante la trascendencia de la titularidad de ese material, las cadenas de televisión cuentan con campos o áreas específicas en sus bases de datos dedicadas a la emisión y a los derechos que ostentan, y que constituye un aspecto básico de cara a la reutilización del material.

Los documentalistas reflejan esta situación en la base de datos con el objeto de hacer constar los aspec- tos jurídicos relacionados con su uso. Así se mencionan la propiedad y su alcance; es decir, cuáles son los derechos que detenta la empresa televisiva sobre un determinado material, así como la fecha de inicio y final de los mismos.

Respecto a la emisión, se anotan en las respectivas bases de datos factores tales como: ámbito geográfico; canal y/o programa de emisión; periodicidad; número de veces que se ha emitido el material; fecha, día y hora de emisión (esta información también se indica para las reemisiones). En el caso de las televisiones autonómicas también se menciona si existen imágenes cedidas por parte de la Federación de Organismos de Radio y Televisión Autonómicos (Forta) y si dicho material ha sido emitido previamente por alguna de las cadenas que integran este organismo.

Por tanto, y como se verá a continuación, no sólo se debe estudiar la titularidad autoral del material informativo per se sino también la de la propia base de datos en la que se archivan. Su régimen jurídico es bien distinto y como se muestra a continuación sus peculiaridades también.

\section{Régimen jurídico de autoría sobre las bases de datos audiovisuales}

2.1. De la protección de los autores de obras literarias a la protección de los autores de bases de datos: aproximación

Inevitablemente al hablar de los medios de comunicación, del material básico que manejan en sus bases de datos y de su régimen de propiedad intelectual, es necesario referirse a la propia evolución del derecho de autor y de sus rasgos característicos. Porque su configuración jurídica actual debe mucho, por no decir todo, a la evolución tecnológica y, dentro de ésta, a la creación de nuevos medios, soportes y productos de comunicación tales como la radio, la televisión, los programas de ordenador y/o las bases de datos.

Además el comercio internacional constante de productos y soportes, consecuencia de la invención de la imprenta en el siglo XV, dificulta deslindar la evolución del derecho de autor en el ámbito español de su evolución supranacional, puesto que las actuales tecnologías de la información requieren, por su misma esencia globalizadora, soluciones universales que en el ámbito europeo se agudizan ante la necesaria armonización de la legislación de los estados miembros de la UE.

Desde esta perspectiva la protección de la titularidad de las bases de datos por el derecho de autor constituye un eslabón más en el desarrollo de esta figura que para la legislación supranacional cobró relevancia a partir de finales del siglo XIX. 
El punto de arranque lo constituyó en 1886 el Convenio de Berna, que dio protección internacional en primer lugar a los creadores de obras escritas en general, con independencia de que se tratase de creaciones literarias o artísticas. De forma particular esa protección se concretó en libros, folletos y demás escritos, obras dramático-musicales, composiciones musicales con o sin palabras, obras de dibujo, pinturas, esculturas, grabados, litografías, ilustraciones, mapas, planos, croquis, obras plásticas relativas a la geografía, a la topografía, a la arquitectura o a las ciencias en general. Es decir, se protegió "toda reproducción literaria, científica o artística que pudiera ser publicada por cualquier forma de impresión o de reproducción"s.

A partir de esta base, y en décadas posteriores, el texto se modificó para ir añadiendo al objeto de protección aquellos materiales cuyo origen radicaba en nuevas invenciones tecnológicas.

Así, en 1896 el Acta adicional de París incluye la fotografía dentro del catálogo de obras protegidas, casi sesenta años después de que Françoise Arago presentara en París el daguerrotipo (el 10 de agosto de 1839). Creado por Niepce y Daguerre permitía la captación de imágenes y su posterior reproducción, constituyéndose en el modelo primitivo a partir del cual se desarrollaría la cámara fotográfica ${ }^{6}$.

Pero el anacronismo que se produjo en la protección jurídica de la fotografía no fue el único. Sin ir más lejos, el cine documental iniciado en 1895 por los hermanos Lumière ${ }^{7}$ no obtuvo protección hasta la Revisión de Roma de 1928 y la Revisión de Bruselas de 1948. Aunque en 1908 en Berlín se había establecido el derecho de reproducción mecánica como distinto al de reproducción de las obras impresas, el cine continuó prácticamente desprovisto de protección al exigírsele que poseyera un carácter original en "las disposiciones escenográficas o combinaciones de incidentes representados" ", algo que, como ya se indicó, aún no sucedía. En Roma se dará un paso adelante al facilitarse su protección con independencia de la plasmación de la personalidad del autor o del hallazgo de la citada originalidad. Finalmente en Bruselas se acordó el reconocimiento de toda obra cinematográfica como original en sí misma, zanjándose así el asunto más de cincuenta años después de su invención.

Pero este derecho de reproducción mecánica, como facultad del derecho de autor reconocido en 1908, abarcó por su propia terminología bastante más que las reproducciones cinematográficas. Se extendió también a la reproducción de las grabaciones sonoras que desde 1877 con el primer prototipo de Edison ${ }^{9}$ venían perfeccionándose. Como consecuencia directa de estas reproducciones surgiría el derecho de ejecución pública como facultad del autor para autorizar o prohibir la escucha en público de sus grabaciones.

La grabación sonora, perfeccionada a través del magnetófono, constituyó uno de los pilares técnicos básicos en el desarrollo de la radio como medio de difusión. Fue en 1920 en la ciudad estadounidense de Pittsburgh cuando oficialmente comenzó la historia internacional de la radiodifusión sonora ${ }^{10}$.

Entonces se hizo necesario dar un paso jurídico más hacia un nuevo modo de "ejecución pública", distinto a la reproducción magnetofónica, que se concibió como derecho de radiodifusión o broadcasting right en la Revisión de Roma de 1928. Este derecho se consagró como la facultad del autor para autorizar o prohibir la comunicación de sus obras a un público indeterminado (la audiencia, aún no cuantificable) mediante la propagación de ondas por el espacio aéreo.

Pero, nuevamente, la tecnología se adelantaría al derecho en 1928 con la televisión, en plena fase experimental en los EUA y Alemania, país éste que puso en marcha los primeros servicios televisivos oficiales siguiendo los hallazgos realizados por el británico John L. Baird" .

No obstante, en el caso de la televisión cuyo soporte de difusión eran también las ondas hertzianas existía la posibilidad de aplicar el derecho de radiodifusión como sistema de protección, dado que éste no se había especificado como exclusivamente sonoro y por tanto podía abarcar perfectamente la difusión de imágenes. Aún así se plantearon dudas sobre la oportunidad de esta fórmula y oficialmente no es hasta el Acta adicional de Berna de 1948 cuando se produce la necesaria asimilación al entenderse que la radiodifusión puede referirse a sonidos, signos y/o imágenes.

A la vez se instituyó el derecho de comunicación al público como una nueva facultad de difusión no circunscrita en exclusiva a los medios inalámbricos o por ondas ${ }^{12}$.

Posteriormente, en 1962 y 1963, el lanzamiento de los satélites estadounidenses Telstar y Syncom facilitó, entre otras aportaciones, la emisión de programas televisivos sobre áreas geográficas más extensas que las alcanzadas hasta entonces mediante ondas hertzianas, dando lugar al inicio de la internacionalización de las emisiones $^{13}$. Con objeto de encauzar esta realidad se firmó un nuevo acuerdo en Bruselas en 1974, en el que se reconocieron: el derecho de los organismos de radiodifusión vía satélite a autorizar o prohibir la reemisión de sus emisiones; su derecho a autorizar o prohibir la difusión de esas emisiones por medio del cable; su derecho a autorizar o prohibir la comunicación al público de las mismas emisiones por cualquier otra 
clase de medios; y su derecho sobre la fijación de sus emisiones y la radiodifusión de esas mismas fijaciones o grabaciones.

A partir de este reconocimiento el derecho de autor evolucionaría hacia la protección de nuevas obras, más que de nuevos modos de transmisión, y de los sujetos que sin ser autores intervenían en la creación y difusión de las mismas (productores, músicos o artistas en general).

Entre estas obras, inevitablemente ligadas a la incipiente sociedad de la información, se hallaron todas aquellas que de uno u otro modo provenían del desarrollo informático o cuya explotación masiva facilitaba éste. De cualquier forma curiosamente su protección no se hizo a priori en el ámbito de los tradicionales convenios internacionales sobre derechos de autor, sino en el marco de acuerdos puramente económicos sobre comercio internacional, tal como fue el caso del GATT $^{14}$.

En 1994, y a través de las negociaciones de la Ronda Uruguay del GATT, se había llegado a la conclusión de la necesidad de incluir un apartado sobre los Aspectos de los derechos de propiedad intelectual relacionados con el comercio (Adpics)" ${ }^{\prime 15}$, dada la trascendencia económica que poseían dentro del comercio internacional. De ahí que se establecieran algunos principios jurídicos básicos y flexibles con el fin de conseguir la mayor adhesión internacional posible.

Extrañamente se optó por la protección de los programas informáticos mediante su asimilación con las obras literarias tal y como éstas se entienden en el texto básico del Convenio de Berna, tanto en lo que respecta a su código fuente (el lenguaje técnico en el que se escribieron las instrucciones creadoras del programa) como en lo concerniente a su código objeto (la traducción de esas instrucciones, realizada por un mecanismo compilador, de forma que el programa pueda ser ejecutado por el ordenador) ${ }^{16}$.

En cuanto a las bases de datos, su protección genérica como obras de autor se realizó mediante su asimilación conceptual con las compilaciones (recopilaciones), aunque siempre en función de la originalidad de la selección y/o estructuración de los contenidos en ellas recogidos.

\subsection{El derecho de autor sobre las bases de da- tos: especificidades de la legislación comunitaria y española}

Tanto el acuerdo GATT de 1994, como dos años más tarde con el Protocolo adicional al Convenio de Berna auspiciado por la OMPI, se optó por dar la ya citada protección genérica a los autores de las bases de datos en los siguientes términos:
—Acuerdo GATT 1994, artículo 10: "2. Las bases o compilaciones de datos, tanto legibles a través de ordenador como en cualquier otra forma, y que por razón de su selección o estructuración de contenidos constituyan una creación intelectual, se protegerán como tales. Dicha protección que no se extenderá a los datos o al material primario en sí mismo, se hará sin perjuicio alguno para cualquier copyright que exista sobre los datos o el citado material" $"$.

\section{«Tanto periodistas como docu- mentalistas renuncian a sus derechos de autor por vía con- tractual laboral»}

- Protocolo adicional al Convenio de Berna 1996, artículo 5: "Las compilaciones de datos o de otros materiales en cualquier forma, que por razones de la selección o disposición de sus contenidos constituyan creaciones de carácter intelectual están protegidas como tales. Esa protección no abarca los datos o materiales en sí mismos y se entiende sin perjuicio de cualquier derecho de autor que subsista respecto a los datos o materiales contenidos en la compilación"18.

A destacar de ambos textos, y como punto de partida de la base de la protección en el caso de las bases de datos, que dicha protección no recae en ningún caso sobre su contenido (los materiales que se hallen en ella, que habrán de protegerse por su propia vía específica). En segundo lugar, que la originalidad en la elaboración de esa base de datos constituye la clave para que se convierta en objeto del derecho de autor.

El sentido de esta segunda pero importantísima premisa es que el requisito de originalidad es desde siempre el elemento clave (y diferenciador entre obras similares) para la protección de cualquier creación bajo el derecho de autor. De ahí que en el caso de las bases de datos la selección original de contenidos se plasme en la compilación de elementos hasta entonces no aglutinados; y su estructuración original radique en la definición de parámetros estéticos y de funcionamiento distintos de los empleados hasta la fecha. De este modo, en el caso de las bases de datos audiovisuales sus creadores habrán de prestar especial atención en su elaboración no sólo a qué materiales compilan, sino a cómo se realiza dicha compilación y cuáles son las posibilidades de interactuación con el usuario que dicha herramienta ofrece, puesto que de ello, más que de un diseño más o menos atractivo y/o diferenciado, dependerá su protección efectiva.

Pero aunque los textos aludidos contengan sólo un primer principio de protección genérico marcan la pauta a partir de la cual se habrá de elaborar el resto del contenido del derecho de autor sobre las bases de 
datos televisivas que, como se puede apreciar a partir de ambas citas legales, posee un carácter eminentemente "contenedor" o función de "continente". Pese a la parquedad y generalidad de los términos empleados, parece obvio dirigir a continuación el estudio hacia dos cuestiones:

-El software empleado en su creación y que evidentemente condiciona su originalidad, puesto que configura los parámetros capaces de diferenciar unas aplicaciones de otras.

-El resto del contenido del derecho de autor sobre estas obras, que remite a las cuestiones de las facultades concedidas al autor sobre su obra, las excepciones a las mismas, o a su plazo temporal de protección, entre otras.

a. Sobre la titularidad del software creador/gestor de la base de datos. Como punto de partida, conviene tener en cuenta las siguientes cuestiones que, por otro lado, no se deben entremezclar:

- Toda base de datos televisiva automatizada descansa sobre el hecho de haber sido creada a partir de un programa informático, que facilita su gestión, tal y como se ha indicado.

-Dicha creación contiene a veces particularidades exigidas por la empresa de televisión que la encarga y compra.

-Dicho encargo y compra no implica la propiedad de los contenidos que posteriormente se incluyan en la base de datos.

-Quienes trabajan en los centros y/o servicios de documentación de las emisoras no mantienen ningún tipo de relación de propiedad sobre la base y su contenido, puesto que su función es la de documentalistas, en ningún caso la de creadores de la base o de su contenido (con las posibles excepciones que la realidad imponga, lógicamente).

A partir de aquí la cuestión de la autoría del software de almacenamiento y gestión ofrece dos posibilidades: que se trate de un programa ya existente comercializado en el mercado y por tanto que la cadena de televisión posea un derecho de uso profesional sobre la copia adquirida; o bien que se trate de una herramienta creada ad hoc, por encargo, para una determinada empresa.

El primer caso no plantea ninguna cuestión respecto al tema de este artículo, puesto que se trata de la adquisición de una licencia comercial de uso idéntica a la que se obtiene al comprar cualquier otro producto ofimático (y las cuestiones autorales, por tanto, caen lejos del alcance de la empresa de televisión). Por otra parte, el segundo caso sí nos adentra en las peculiari- dades jurídicas del derecho de autor y su actual contenido a partir de la legislación española e, inevitablemente, comunitaria.

Así, cabe comenzar subrayando que tanto la $D i$ rectiva de la UE sobre protección jurídica de programas de ordenador de $1991^{19}$ como el Texto refundido español de propiedad intelectual de $1996^{20}$, otorgaron al software protección como obra literaria, cualquiera que sea su forma de expresión, pero sin incluir en la misma las ideas lógicas, algoritmos, interfaces y lenguajes de programación empleados para su creación. Es decir, se protege el programa final como tal, en cuanto resultado, tanto en su código fuente como en su código objeto, pero no las distintas fases del proceso creativo.

Como consecuencia de este modo de protección, y de acuerdo con la doctrina del derecho de autor, su titularidad recae, como norma genérica, sobre la persona o personas físicas que lo crean, o bien sobre la persona jurídica que se considere titular de los derechos, en este caso el empresario o la empresa para el/la que el creador trabaje. En lo tocante a las bases de datos televisivas plantea dos posibilidades: que se contrate directamente la creación de un programa informático a un trabajador por cuenta propia o que se contrate su creación a una empresa informática.

En ambos casos estaremos ante la figura del llamado autor asalariado, pero también de lo que podríamos denominar "empresa asalariada"; y en ambos asimismo el documento contractual previo a la creación de la obra contendrá de ordinario una cláusula donde se estipule la reserva de la titularidad de derechos a favor de quien realiza el encargo, es decir, la empresa de televisión. De este modo una vez entregado el software gestor, y recibida la contraprestación económica correspondiente, la empresa televisiva pasa a detentar los derechos de explotación y la titularidad del programa. De hecho así lo especifica la propia Directiva comunitaria citada al afirmar que "cuando un trabajador asalariado cree un programa de ordenador en el ejercicio de las funciones que le han sido confiadas, o siguiendo las instrucciones de su empresario, la titularidad de los derechos económicos correspondientes al programa de ordenador así creado corresponderán exclusivamente al empresario, salvo pacto en contrario" ${ }^{21}$.

Y del mismo modo, entre la persona individual que crea el programa y el empresario informático para el que trabaja se produce una relación del mismo tipo, basada en la renuncia de derechos de autor del primero a favor del segundo, por medio de su relación laboral. Sin embargo, retendrá siempre el autor-asalariado los derechos morales de autor que en España se concretan en: 
"1. Decidir si su obra ha de ser divulgada y en qué forma.

2. Determinar si tal divulgación ha de hacerse con su nombre, bajo seudónimo o signo, o anónimamente.

3. Exigir el reconocimiento de su condición de autor de la obra.

4. Exigir el respeto a la integridad de la obra e impedir cualquier deformación, modificación, alteración o atentando contra ella que suponga un perjuicio (...).

5. Modificar la obra respetando los derechos adquiridos por terceros (...).

6. Retirar la obra del comercio por cambio de sus convicciones intelectuales o morales, previa indemnización de daños y perjuicios a los titulares de derechos de explotación.

7. Acceder al ejemplar único o raro de la obra $(\ldots)^{\prime 22}$.

Lógicamente, en caso de que autor y explotador de la obra coincidiesen en la misma persona física también los derechos morales de autor recaen sobre ella.

Cuestión distinta será, obviamente, los términos en los que el contrato del encargo de la obra establezca la titularidad de derechos de explotación sobre la misma, es decir: las condiciones bajo las cuales se realiza la renuncia a los derechos de autor por parte del autorasalariado o empresa-asalariada y en las que el nuevo titular podrá ejercerlos (asunto éste que se corresponde con un pacto entre ambas partes).

\section{«La originalidad en la elabora- ción de la base de datos cons- tituye la clave para que se con- vierta en objeto del derecho de autor»}

El titular de los derechos, sea quien fuere (la empresa televisiva o el creador de software que comercializa copias) disfrutará como tal figura de una serie de derechos que abarcan, según la Directiva comunitaria: su reproducción total o parcial por cualquier medio o forma; su traducción, adaptación, arreglo o transformación y, lógicamente, la reproducción de su resultado; la venta y alquiler del mismo y de sus copias legítimas $^{23}$.

Existen también excepciones al ejercicio de estas facultades, que en el caso concreto del programa informático gestor se refieren a ciertas adaptaciones que quizá resulten necesarias como consecuencia de las exigencias específicas del usuario/comprador, así como del entorno informático al que se incorpora. De ahí que el titular pueda: reproducir, traducir, adaptar, arre- glar o transformar un programa cuando ello sea necesario para su utilización; realizar una copia de salvaguarda en las mismas circunstancias; observar, estudiar y verificar el programa cuando ello tenga lugar durante las operaciones de carga, visualización, transmisión o almacenamiento; y, finalmente, reproducir y traducir el código fuente cuando ello sea imprescindible para su interoperabilidad con otros programas ${ }^{24}$.

Finalmente cabe señalar que si bien los derechos morales de autor gozan de la cualidad de imprescriptibilidad, los de explotación se extenderán tan sólo durante la vida del autor o titular más setenta años tras su muerte.

b. Sobre la titularidad de la base de datos como contenedor de información. En cuanto a las especificidades de su titularidad, el requisito de originalidad que su protección general plantea pone de manifiesto dos cuestiones a la hora de analizar su contenido:

-En qué medida se puede considerar que la selección de ítems informativos y su archivo en una base audiovisual constituye algo original.

- Como consecuencia de la idea anterior, que el mayor grado de originalidad deberá recaer, por tanto, en el sistema de gestión (almacenaje y recuperación) implantado.

Así lo reconoce la propia Directiva sobre protección de bases de datos, incorporada a la legislación española ${ }^{25}$ cuando afirma en sus considerandos y en su articulado:

“(15) Considerando que los criterios en virtud de los cuales las bases de datos son susceptibles de la protección de derechos de autor deben limitarse al hecho de que la selección o disposición del contenido de la base de datos constituya una labor de creación propia del autor; y que esta protección se refiere a la estructura de la base de datos" ${ }^{\prime 26}$.

Artículo 3. 1. "De conformidad con lo dispuesto en la presente Directiva, las bases de datos que por la selección o la disposición de su contenido constituyan una creación intelectual de su autor estarán protegidas, como tal creación, por los derechos de autor. No serán de aplicación otros criterios para determinar si tales bases de datos son susceptibles de dicha protección" ${ }^{27}$.

Tal y como sucedía en el caso del software, que en realidad es una especie de "reverso de la moneda" con respecto al resultado final, la base de datos, la titularidad inicial, en caso de que se reconozca su originalidad, recae sobre su auténtico creador. Sin embargo, precisamente por tratarse del resultado final del proceso de creación informática puede poseer un titular distinto al del propio software, en función de las estipulaciones contractuales del encargo antes mencionadas. 
De hecho, la estructura resolutiva de esta cuestión es idéntica a la del caso anterior, y por tanto de ordinario será la empresa de televisión la que detente nuevamente los derechos de explotación de la base de datos; mientras que el creador de la misma, distinto o no del creador del software gestor, volverá a obtener la figura de autor asalariado o "empresa asalariada".

Así, en primer lugar, tanto la titularidad del programa informático como del conjunto de la base de datos pertenecerá básicamente al empresario por ser quien realiza la inversión económica necesaria para su creación; puesto que desde este punto de vista la legislación, aun reconociendo que la autoría pertenece a quien de facto crea el software o la base de datos, entiende que la titularidad de los derechos de explotación pasa contractualmente a quien compra el producto, considerándose quien lo crea autor-asalariado.

Al margen de los derechos morales ya enumerados para el caso español, el autor/titular de los derechos de explotación dispondrá, en el caso de la base de datos, de la facultad de autorizar o prohibir: su reproducción temporal o permanente, total o parcial, por cualquier medio y de cualquier forma; su traducción, adaptación, reordenación y cualquier otra modificación, y la muestra de su resultado; cualquier forma de distribución al público de la base de datos o de copias de la misma; y toda forma de comunicación, exhibición o representación ${ }^{28}$.

Estas facultades, que también se extienden durante la vida del autor más setenta años tras su muerte, presentan también excepciones a su ejercicio que se concretan en: la comisión de cualquiera de los actos antes citados cuando sean necesarios para el acceso al contenido de la base de datos y para su utilización; la reproducción para fines privados que, curiosamente, sólo se autoriza en el caso de las bases de datos no electrónicas; el uso docente e investigador (es decir, propósitos no comerciales) indicando la fuente originaria de la información; y la utilización para fines de seguridad pública o a efectos de un procedimiento judicial.

\subsection{El derecho sui generis del fabricante de la base de datos}

Sin embargo, este panorama jurídico medianamente claro se complica en el caso de las bases de datos a raíz de la introducción con la Directiva comunitaria de un nuevo derecho afín próximo al de autor, pero no totalmente equiparable: el derecho sui generis del fabricante de la base de datos.

Su razón de ser radica en la observación de dos circunstancias: la necesidad de reconocer el esfuerzo de recopilación e indización de contenidos no sujetos al derecho de autor realizado por quienes se encargan de las tareas de recolección y almacenaje del material; y la necesidad de reconocer también la inversión de tiempo, dinero y esfuerzo de aquellos que, sin aportar originalidad en la estructura del producto, sí han aglutinado contenidos hasta entonces no ordenados ${ }^{29}$.

De este modo se configura un derecho de muy marcado cariz comercial destinado a premiar al fabricante de la base de datos como persona encargada de la búsqueda y recopilación del contenido de la misma. Es pues un derecho extremadamente enfocado hacia las bases de datos que se comercializan offline u online, más que hacia aquellas que se elaboran expresamente para/dentro de un medio de comunicación y cuya gestión y utilización de contenidos no lo trasciende.

Esto plantea cuestiones respecto a la titularidad de derechos que los documentalistas poseen sobre la base de datos a través del derecho sui generis, así como respecto a los derechos del empresario. Para una duración de 15 años a partir del 1 de enero del año siguiente al que haya finalizado su labor la Directiva marca:

Artículo 7. 1: "Los estados miembros dispondrán que el fabricante de la base de datos pueda prohibir la extracción y/o reutilización de la totalidad o de una parte sustancial del contenido de ésta, evaluada cualitativa o cuantitativamente, cuando la obtención, la verificación o la presentación de dicho contenido representen una inversión sustancial desde el punto de vista cuantitativo o cualitativo" ${ }^{\prime 30}$.

De este modo tan ambiguo se ofrecen ciertos derechos, aunque mínimos, al recolector de los contenidos de la base de datos y, por extensión, sobre el propio contenido (lo que resulta contradictorio con la norma genérica sobre titularidad de bases de datos) con respecto a las posibilidades de que sea reutilizado ilícitamente en otros soportes y/o productos.

En el supuesto de los documentalistas o recolectores de información, si trabajan para la propia empresa de televisión como miembros de su plantilla, la cuestión vuelve a resolverse a través de la figura del autor asalariado, que implica su renuncia por medio de su contrato laboral a todo tipo de derechos de propiedad intelectual a cambio de su salario mensual. En lo que a la empresa de televisión se refiere (del empresario, en definitiva) su labor como inversor (en cuanto a la financiación) le confiere la posibilidad de pactar con el creador original, en el momento del encargo, una posible titularidad de derechos a través de esta vía que es paralela y no excluyente de la del titular de la base de datos.

En consecuencia, sus derechos sui generis de explotación se ven solamente limitados por los del usua- 
rio legítimo al que se le permite: extraer y/o reutilizar partes del contenido siempre y cuando no sean sustanciales. En cambio se le prohíbe la comisión de actos contrarios a la explotación normal de la base, así como cualquier otra acción que perjudique al fabricante y/o a los titulares de derechos de las obras recogidas en ella.

Más allá de este derecho básico constituyen también excepciones: la extracción para fines y uso privados del contenido de una base no electrónica; la extracción con fines ilustrativos de enseñanza o de investigación científica, siempre que se indique la fuente y en la medida justificada por el objetivo no comercial que se persiga; y por último la extracción y/o reutilización para fines de seguridad pública o a efectos de un procedimiento administrativo o judicial.

\section{Régimen jurídico de autoría sobre la información periodística de actualidad en televisión}

Pero tal y como ya se dijo, hemos atendido en el epígrafe anterior al régimen de propiedad intelectual de la base de datos audiovisual en sí misma, tomada como lugar de almacenaje de la información audiovisual de actualidad, y no a las propias piezas informativas que se manejan en ella, que por otra parte y además la propia normativa comunitaria y española sobre bases de datos deja a un lado de la protección por considerarse contenido de la base que posee su propio sistema de protección.

En efecto, así es, especialmente si se tiene en cuenta que la información periodística de actualidad se rige por un sistema autoral particular, diferente al del resto de las obras literarias, artísticas y/o científicas que se insertan en el régimen del derecho de autor.

Por ello se impone la necesidad de explicar cuál es su régimen ordinario de autoría que, al margen de muy escasas peculiaridades nacionales, se ha extendido unitariamente en el marco internacional a partir del año 1971 con la Revisión de París del Convenio de Berna, donde se optó por la búsqueda del equilibrio entre titularidad y explotación de derechos, y ejercicio efectivo del derecho a la información del ciudadano.

Artículo 2, párrafo 8: "La protección [dada al resto de las obras] no se aplicará a las noticias del día ni a los sucesos que tengan el carácter de simples informaciones de prensa" ${ }^{31}$.

Para entender el porqué de esta desprotección es necesario acudir a la explicación del concepto de originalidad, básico en el derecho de autor, como ya se mencionó: dado que los textos (escritos, sonoros, audiovisuales) periodísticos de actualidad se construyen habitualmente empleando un lenguaje y estilo especí- fico, prácticamente similar (aunque en función del medio) se le presupone a la noticia una falta llamativa de originalidad en su elaboración y por tanto la carencia del rasgo más importante para ser objeto de protección bajo el derecho de autor. A todo ello hay que sumar el derecho a la difusión informativa como uno de los componentes básicos del derecho humano a la información.

Sin embargo esto no significa que la comunicación pública de noticias pueda hacerse indiscriminadamente; que no existan derechos sobre el modo/medio/soporte de difusión; que, en el caso de la televisión, una noticia montada y difundida pueda ser libremente emitida, tal cual, por otro medio; o que cualquier medio de comunicación pueda recoger y difundir, por ejemplo, los textos elaborados por una agencia de noticias sin su consentimiento.

La aparente desprotección de la información periodística de actualidad se refiere esencialmente a cuatro cuestiones:

- La posibilidad de reutilizar materiales en bruto de titularidad ajena.

- La perspectiva de volver a usar puntualmente y con fines informativos materiales editados/netos de titularidad ajena.

-El hecho de que el periodista, como autor-asalariado, cede sus derechos comerciales al empresario a cambio de un sueldo o remuneración por pieza.

- La obligación de que esta libre reutilización se haga siempre bajo una serie de condiciones.

La principal condición en el ámbito internacional, y por ende en el caso español, es la de cumplir con la cita pública obligada de la fuente de la cual se ha obtenido la información (imagen, sonido, en este caso) como modo de reconocimiento básico de los derechos morales del autor, es decir, de los derechos del autor que no son ni negociables ni cesionables. El resto de las condiciones poseen un carácter más genérico pero que tampoco conviene olvidar: que las leyes nacionales autoricen este tipo de uso; que se haga expresamente sobre artículos informativos de actualidad (referidos a temas públicos de discusión como política, economía, etc.); que se hayan radiodifundido por televisión previamente; y que dicho uso no haya sido prohibido expresamente por el titular.

Es decir, que en el caso de las noticias audiovisuales (televisivas) de producción ajena (difundidas por otros medios de comunicación) su empleo es posible bajo el respeto a una serie de obligaciones más morales que comerciales; que en el caso de que una noticia/material se halle en la base de datos informativa de una televisión y no haya sido difundida previamente 
habrá de negociarse un acuerdo específico de utilización; y que en el caso de las noticias de producción propia se reconoce al medio su titularidad, pero será de aplicación el mismo régimen autoral que para el caso contrario.

Como expresa el artículo 33 del vigente Texto refundido de la ley de propiedad intelectual española con respecto a las obras no susceptibles de protección bajo ella:

"1. Los trabajos sobre temas de actualidad difundidos por los medios de comunicación social podrán ser reproducidos, distribuidos y comunicados públicamente por cualesquiera otros de la misma clase, citando la fuente y el autor si el trabajo apareció con firma y siempre que no se hubiese hecho constar en origen la reserva de derechos. Todo ello sin perjuicio del derecho del autor a percibir la remuneración acordada o, en defecto de acuerdo, la que se estime equitativa.

Cuando se trate de colaboraciones literarias será necesaria en todo caso la oportuna autorización del autor.

2. Igualmente, se podrán reproducir, distribuir y comunicar las conferencias, alocuciones, informes ante los tribunales y otras obras del mismo carácter que se hayan pronunciado en público siempre que esas utilizaciones se realicen con el exclusivo fin de informar sobre la actualidad. Esta última condición no será de aplicación a los discursos pronunciados en sesiones parlamentarias o de corporaciones públicas. En cualquier caso queda reservado al autor el derecho a publicar en colección tales obras"”2.

Es más, la especificidad del régimen de propiedad intelectual de las noticias es tal que incluso cuando en su contenido se incluye la reproducción de una obra artística, literaria o científica (un fragmento musical, dramático, etc.) su difusión es posible sin necesidad de acuerdo o compra de derechos, aunque sólo en la medida en que lo justifique la finalidad informativa de su inclusión:

Artículo 35: "1. Cualquier obra susceptible de ser vista u oída con ocasión de informaciones sobre acontecimientos de actualidad puede ser reproducida, distribuida y comunicada públicamente, si bien sólo en la medida que lo justifique dicha finalidad informativa $(\ldots)^{n_{33}}$

Cuestión distinta es, obviamente, la que atañe a la suscripción de una emisora de televisión a una agencia de noticias con el fin de recibir informaciones audiovisuales de actualidad con vistas a su emisión. En este caso, y como se deduce a partir de lo expuesto en los párrafos anteriores, no se trata del recurso a la reutilización de imágenes/sonidos difundidos previamente por otra emisora de televisión; ni tan siquiera se trata de un acuerdo puntual de intercambio de piezas informativas completas/editadas, o de textos audiovisuales en bruto no emitidos aún. Se está pues ante un caso de utilización de unos servicios comerciales de información sin los cuales los informativos de la emisora (especialmente si es local o regional) carecerían probablemente de buena parte de las noticias que habitualmente los rellenan.

Precisamente por tratarse de servicios comerciales, la relación se rige por un criterio puramente mercantilista en el que el cuidado público de los aspectos morales del derecho de autor (en concreto, la cita de la fuente) deja de ser necesario. Importan ahora tan sólo los términos de explotación acordados en el contrato, entre los que deben incluirse (y así ocurre habitualmente con los formularios contractuales ya consolidados):

—La identificación de las partes contratantes, en este caso agencia y emisora.

-El objeto del contrato, es decir, qué tipo de cesión se hace (exclusiva o no) sobre qué obras (todas las noticias, un número determinado, sólo las de un tema específico, etc.) y para qué tipo de utilización (un único pase al día, varios, etc.).

- Las modalidades de explotación contempladas, esto es, radiodifusión televisiva por ondas hertzianas, por satélite, por cable, y/o en internet; y si existe la posibilidad o no de modificar esas imágenes/audios, adaptarlos en función del soporte o alterarlos con cualesquiera otros fines.

—La duración del acuerdo, que suele ser de un año.

-El territorio geográfico para el cual se cede la utilización de esas noticias.

-El medio o soporte a través del cual se difundirán las informaciones.

—La posibilidad de que el cesionario (la emisora) realice subrogaciones del contrato.

-Finalmente, la remuneración y delimitación de responsabilidades legales.

Por otro lado, el periodista, en caso de realizar su labor dentro de la plantilla de una empresa informativa posee un régimen especial de autoría que se corresponde, una vez más, con el del autor asalariado que realiza una renuncia expresa a sus derechos como una de las cláusulas principales de su contrato de trabajo. Si se tratase de un free lance, que realiza su tarea informativa al margen de las organizaciones informativas típicas (agencias, emisoras, periódicos) la negociación de sus derechos de explotación habrá de dirimirse a 
través del contrato de compra-venta que regule la cesión de su trabajo al medio.

\section{Régimen de las cesiones contractuales de derechos de autor en informaciones de actualidad, software $y$ bases de datos}

Precisamente la cuestión de las cesiones contractuales ha constituido un ítem recurrente en este artículo, a la hora de explicar el encargo, gestión, uso y disfrute de las bases de datos informativas audiovisuales y de su contenido; por lo que la referencia a sus características más básicas merece una atención especial.

Lejos de constituir una cuestión compleja, se trata más bien de un asunto que requiere previsión y diálogo a la hora de ser negociado, puesto que, como se ha visto, abarca cuestiones tan distintas como la compra de imágenes por parte de una cadena de televisión a otra, hasta las condiciones jurídicas para la realización de software por encargo, o la indexación de los contenidos de una base.

\section{«El periodista posee un régi- men especial de autoría que se corresponde con el autor asala- riado»}

De ahí que, teniendo en cuenta las peculiaridades del régimen autoral de cada uno de los productos citados, así como las salvedades y excepciones que un contrato particular puede imponer (como fruto de un acuerdo) es posible listar algunas pautas genéricas a la hora de realizar cualquier contrato de cesión de derechos, con independencia del tipo de producto del que estemos hablando. Isabel Hernando ${ }^{34}$ señala, en el ámbito de la actual sociedad de la información, como elementos comunes a todo contrato de explotación los siguientes, aplicables en este caso a las citadas transmisiones de derechos inter vivos:

\section{-Identificación de las partes contratantes.}

- Objeto del contrato: de qué tipo de cesión o licencia se trata, sobre qué obra y para qué tipo de utilización.

—Enumeración de los derechos electrónicos y no electrónicos cedidos, así como de las modalidades de explotación, especificando hasta el mayor de los extremos posibles las facultades del derecho de autor (reproducción, distribución, comunicación pública y transformación) que se ceden, así como los medios de comunicación para los cuales se otorga la licencia.

-Duración temporal o en número de emisiones, territorio y exclusividad.
-Remuneración.

-Cláusula de garantías y responsabilidad: de forma que se garantice al cesionario el disfrute conforme a la ley de los derechos que adquiere.

-Definiciones de los conceptos que pueden presentar dudas interpretativas.

-Cláusula de confidencialidad, especialmente importante en el caso del software y las bases de datos.

—Reserva de derechos morales y modalidad de su gestión.

- Subrogaciones por parte del cesionario o cesiones a terceros.

-Ejercicio de la defensa y protección del licenciatario, por sí mismo o a cargo de licenciante.

—Ley o leyes aplicables y jurisdicción competente.

Por último, y de modo específico para los programas de ordenador y las bases de datos, aspectos a tener en cuenta en la negociación contractual de cesión de derechos son:

En el caso del software:

- Si se acuerda o no la entrega o no de la documentación técnica y de los manuales de uso que en caso de existir también constituirían objeto de protección.

—La especificación de la titularidad de derechos de explotación y la reserva de derechos de autor a favor del creador original.

- La autorización o no de la reproducción del programa cuando ésta sea necesaria para su carga, presentación, ejecución, transmisión o almacenamiento, conforme a lo marcado por la ley.

- Si se trata de un programa transformado o no, y quién es el titular de dicha transformación.

-El catálogo explícito de los derechos del usuario o cesionario: reproducción o transformación, y corrección de errores, siempre que dichos actos sean necesarios para su utilización; realización de copia de seguridad, bajo la misma condición; observación, estudio o verificación del funcionamiento del software en el transcurso de las operaciones de carga, visualización, ejecución, transmisión o almacenamiento; realización o autorización de versiones del programa o de derivados del mismo, salvo pacto en contrario; reproducción del código y traducción de su forma con vistas a obtener la interoperabilidad con programas creados de forma independiente. 


\section{Versión online de EPI}

\section{Existe una versión electrónica de El profesional de la información, de uso gratuito} para la mayoría de los suscriptores (empresas, organismos, instituciones), que pueden acceder a través de internet a los textos completos y materiales gráficos publicados en la revista.

Más información en: http://www.elprofesionaldelainformacion.com/contenidos.html

En cuanto a las bases de datos, Carrascosa, Pozo y Rodríguez de Castro ${ }^{35}$ proponen dos modelos fundamentales:

1. El contrato de distribución de una base de datos, "que consiste en el destino de la misma hacia su comercialización, a cambio de un precio y durante un período de tiempo determinado". Entre los puntos a tratar en el contrato aparecen:

-Las obligaciones del titular de la obra: aportar los datos de forma accesible y en soporte adecuado al distribuidor, ceder al distribuidor los derechos de explotación, proporcionarle los instrumentos necesarios para la explotación de los datos, e informarle de los criterios empleados en la selección de las fuentes, así como de la finalidad de la explotación.

-Las obligaciones del distribuidor: garantizar suministrando los medios necesarios una buena comercialización y explotación de la obra; adaptar la obra y el equipo informático a la evolución tecnológica y a las necesidades concretas del usuario; establecer algún método de control sobre el acceso a la base de datos; analizar la frecuencia de uso; facturar; redactar y entregar los manuales de utilización; formar al usuario en su uso; dar asistencia técnica al mismo; y en caso de rescisión contractual entregar al titular los programas empleados en la gestión de la obra.

- La duración del contrato.

2. El contrato de uso de la base de datos o de suministro de información que consiste "en la puesta a disposición de la base de datos al usuario, actualización, entrega del thesaurus y manuales de consulta, así como la resolución de consultas y resolución de incidencias conceptuales y funcionales que puedan surgirle". Deberá incluir:

—Las obligaciones del titular de la base de datos: garantizar al usuario la coincidencia entre la información ofertada y la suministrada, responsabilizarse por los daños producidos debido a errores contenidos en los documentos almacenados, e informar sobre los documentos fuente.

-Las obligaciones del distribuidor: definir la oferta de sus servicios; comunicar al usuario las fuentes empleadas en la base de datos, los temas ofrecidos, la cobertura espacial y temporal, los criterios de selección, y el volumen de información; garantizar el secreto de las consultas y su resultado; asesorar sobre las modalidades de acceso a la base de datos y sobre la compatibilidad de los equipos; establecer la oferta de asistencia técnica al usuario, así como la entrega de manuales o la realización de cursillos.

- Las obligaciones del usuario: pagar la tarifa pactada por su uso, que consiste habitualmente en un pago inicial por la conexión, un pago anual por su mantenimiento y la tarifa por el uso de los equipos; garantizar su confidencialidad sobre el código de acceso a la base de datos; y obligar al uso correcto de los documentos facilitados. 


\section{Conclusiones}

La evolución tecnológica y su aplicación al ámbito informativo-audiovisual han condicionado no sólo el trabajo desarrollado por los periodistas sino que ha supeditado también las tareas documentales que se llevan a cabo en las cadenas de televisión, como en cualquier otro medio de comunicación.

La información periodística tiene un régimen especial de derechos de autor caracterizado por una mayor libertad de uso, la cual se consigue gracias a la mención explícita de la fuente informativa. En suma, en este ámbito que nos ocupa el derecho de autor sobre el contenido trabaja de forma distinta, donde la procedencia de los materiales utilizados es importante pero no limita el trabajo informativo.

En el caso de las bases de datos la protección jurídica incide más en cuanto a "archivo" de documentos que en relación con los propios contenidos. Es el mencionado derecho sui generis, el cual implica que la empresa de televisión, al ser coordinadora y compiladora de la selección de los materiales que llegan a la cadena, posea ese derecho sobre todo lo que se almacene.

\section{Notas}

1. Al hablar de información periodística de actualidad nos referimos a las noticias de acontecimientos actuales o actualizados que se comunican por su interés. En el medio televisivo dichas bases de datos están constituidas fundamentalmente por una serie de áreas tales como: Control e identificación (producción, responsabilidad, localización y emisión); Descripción formal (aspectos técnicos y morfológicos); y Contenido (descripción semántica: denotación y connotación).

2. En el campo del audio se registrará "ambiente" o "editado", en función de la procedencia de los elementos sonoros. En la práctica, algunas cadenas de televisión son conscientes de la carga informativa que transmiten ambas bandas (con mayor o menor sincronía) y disponen de campos diferenciados para la información visualizada o referenciada.

3. Martin, James. Organización de las bases de datos. Englewood Cliffs [etc.]: Ed. Prentice/Hall international, 1982, p. 34.

4. En este sentido Giménez Toledo dice que "en la medida en que los mensajes informativos de ayer son la base de los mensajes informativos futuros es muy importante que la información que vayan generando los distintos medios se vaya almacenando, tratando y difundiendo de forma sistemática, constituyendo de esta manera sistemas de información al servicio del periodista". Giménez Toledo, Elea. "Las bases de datos para los profesionales de la comunicación”. En: Teoría y práctica de la documentación informativa. Barcelona: Ariel, 2002, p. 176.

5. Lipszyc, Delia, op. cit., pp. 624-625.

6. Azurmendi, Ana. El derecho a la propia imagen. Su identidad y aproximación al derecho a la información. México: Fundación Manuel Buendía y Universidad Iberoamericana, 1998, p. 18.

7. Palau, José. Historia del cine. Barcelona: Seix Barral, 1946, p. 9.

8. Lipszyc, Delia, op. cit., p. 633.

9. El invento de Edison se perfeccionó en 1889 con el gramófono de Bell; en 1925 con el gramófono eléctrico; y en 1946 con la aparición del magnetófono.

10. Borderia, Enric, [et al.]. Historia de la comunicación social. Voces, registros y conciencias. Madrid: Síntesis, 1996, p. 380.

11. Ibídem, p. 396.
12. Stewart, Stephen, op. cit., p. 914.

13. Borderia, Enric, [et al.], op. cit., pp. 398-399.

14. General agreement on trade and tariffs (Acuerdo general sobre comercio y aranceles), promovido por la Organización Mundial del Comercio.

15. El Acuerdo Adpics también se conoce por su denominación en inglés: Trade related aspects in intellectual property rights (TRIPs).

16. Correa, Carlos. Acuerdo TRIPs. Régimen internacional de la propiedad intelectual. Buenos Aires: Ediciones Ciudad Argentina, 1996, p. 58.

\section{Ibídem.}

18. Organización Mundial de la Propiedad Intelectual, Protocolo adicional al Convenio de Berna, Tratado sobre Derecho de Autor. Ginebra, 1996. Fotocopia facilitada por la OMPI.

19. Vid. Consejo, Directiva sobre la protección jurídica de programas de ordenador, 91/250/CEE, de 14 de mayo de 1991.

20. Real Decreto-Legislativo 1/1996, de 12 de abril, por el que se aprueba el Texto refundido de la ley de propiedad intelectual, regularizando, aclarando y armonizando las disposiciones legales vigentes sobre la materia.

21. Ibídem, artículo 2 de la Directiva, pp. 122-144.

22. Artículo 14 del Real Decreto-Legislativo 1/1996, de 12 de abril, por el que se aprueba el Texto refundido de la ley de propiedad intelectual, regularizando, aclarando y armonizando las disposiciones legales vigentes sobre la materia.

23. Artículo 4 de la Directiva sobre la protección jurídica de programas de ordenador, op. cit., pp. 122-144.

24. Ibídem, artículos 5 y 6, pp. 122-145.

25. Ley 5/1998, de 6 de marzo, de incorporación al derecho español de la Directiva 96/9/CE sobre la protección jurídica de bases de datos, de 11 de marzo de 1996.

26. Parlamento Europeo y Consejo, Directiva sobre la protección jurídica de las bases de datos (96/9/CE), de 11 de marzo de 1996, pp. 77/21.

27. Ibídem, pp. $77 / 25$.

28. Ibídem, artículo 5, pp. 77/25. En este caso las excepciones a favor del usuario se refieren a: la comisión de cualquiera de los actos antes citados cuando sean necesarios para el acceso al contenido de la base de datos y para su utilización; la reproducción para fines privados que, paradójicamente, sólo se autoriza en el caso de las bases de datos no electrónicas; la utilización con fines docentes e investigadores, indicando la fuente originaria de la información; la utilización para fines de seguridad pública o a efectos de un procedimiento judicial; y cualesquiera otras que determinen las leyes de cada país.

29. Ibídem, considerandos 39 y 40, pp. 77/22.

30. Ibídem, pp. $77 / 25$.

31. Lipszyc, Delia, op. cit., p. 694.

32. Real Decreto-Legislativo 1/1996, de 12 de abril, por el que se aprueba el Texto refundido de la ley de propiedad intelectual, regularizando, aclarando y armonizando las disposiciones legales vigentes sobre la materia.

33. Ibídem.

34. Hernando, Isabel. Productos multimedia y derechos de autor. San Sebastián: LC, 1997, pp. 157-158.

35. Carrascosa, V.; Pozo, María A.; Rodríguez de Castro, E. P. La contratación informática: el nuevo horizonte contractual. Los contratos electrónicos e informáticos. Granada: Comares, 1999, p. 254.

Julián Rodríguez Pardo, María Victoria Nuño Moral, Facultad de Biblioteconomía y Documentación, Universidad de Extremadura, 06071 Badajoz.

mvnunmor@alcazaba.unex.es

jrodpar@alcazaba.unex.es 